\title{
Decomposition Behavior of Hemicellulose and Lignin in the Step-Change Flow Rate Liquid Hot Water
}

\author{
Xinshu Zhuang • Qiang Yu • Wen Wang • Wei Qi • \\ Qiong Wang $\cdot$ Xuesong Tan $•$ Zhenhong Yuan
}

Received: 6 January 2011 / Accepted: 21 November 2011 /

Published online: 22 January 2012

(C) Springer Science+Business Media, LLC 2012

\begin{abstract}
Hemicellulose and lignin are the main factors limiting accessibility of hydrolytic enzymes besides the crystallinity of cellulose. The decomposition behavior of hemicellulose and lignin in the step-change flow rate hot water system was investigated. Xylan removal increased from $64.53 \%$ for batch system (solid concentration $4.25 \% \mathrm{w} / \mathrm{v}, 18 \mathrm{~min}, 184^{\circ} \mathrm{C}$ ) to $83.78 \%$ at high flow rates of $30 \mathrm{ml} / \mathrm{min}$ for $8 \mathrm{~min}$, and then $10 \mathrm{ml} / \mathrm{min}$ for $10 \mathrm{~min}$. Most of them (80-90\%) were recovered as oligosaccharide. It was hypothesized that the flowing water could enhance the mass transfer to improve the sugars recovery. In addition, the solubilization mechanism of lignin in the liquid hot water was proposed according to the results of Fourier transform-infrared spectroscopy and scanning electron microscopy of the water-insoluble fraction and gas chromatography-mass spectrometry of the water-soluble fraction. It was proposed that lignin in the liquid hot water first migrated out of the cell wall in the form of molten bodies, and then flushed out of the reactor. A small quantity of them was further degraded into monomeric products such as vanillin, syringe aldehyde, coniferyl aldehyde, ferulic acid, and p-hydroxy-cinnamic acid. All of these observations would provide important information for the downstream processing, such as purification and concentration of sugars and the enzymatic digestion of residual solid.
\end{abstract}

Keywords Decomposition $\cdot$ Hemicellulose $\cdot$ Lignin $\cdot$ Step-change flow rate liquid hot water (SCFLHW) · Sweet sorghum bagasse (SSB)

\section{Introduction}

The sweet sorghum bagasse (SSB) is the solid residue from the ethanol fermentation of sweet sorghum, which has been regarded as one of the most promising feedstock source for bio-ethanol production $[5,9,13,14,16]$. Traditionally, SSB is utilized for the animal feed,

X. Zhuang $\cdot$ Q. Yu $\cdot$ W. Wang $\cdot$ W. Qi $\cdot$ Q. Wang $\cdot$ X. Tan $\cdot$ Z. Yuan $(\bowtie)$

Guangzhou Institute of Energy Conversion, Key Laboratory of Renewable Energy and Gas Hydrate,

Chinese Academy of Sciences, Guangzhou 510640, China

e-mail: yuanzh@ms.giec.ac.cn 
papermaking, or combustion. At present, the saccharification of SSB is attracting more global interests due to its prominent content of cellulose and hemicellulose [3, 9, 12, 15]. Among the saccharification technologies available for the production of sugars from lignocellulosic biomass, a conversion process based on the use of cellulolytic enzymes appears to be the most promising for large-scale application. However, the enzymatic hydrolysis of lignocellulose is limited by several factors. Hemicellulose and lignin are the main factors besides the crystallinity of cellulose. The removal of hemicellulose can increase the mean pore size of substrate and therefore increases the probability of cellulose to get hydrolyzed. Also, the removal of lignin can get rid of the shield, preventing the digestible parts of the substrate to be hydrolyzed, and enhance the rate and extent of enzymatic hydrolysis.

Liquid hot water (LHW) processing using pressure to maintain the water in the liquid state at elevated temperatures is a green and attractive approach because it does not require the addition of chemicals such as sulfuric acid, lime, and ammonia [22]. An effective LHW processing generates reactive cellulose fiber, allowing the recovery of most of the pentosan, and only a few of the degradation products that can hinder subsequent hydrolysis and fermentation $[2,8,18]$. Three types of operation mode, batch [18], continuous flow through $[11,20,21]$, and partial flow [10], were typically used. Continuous flow through can improve the hemicellulose sugar yield and also achieve nearly theoretical cellulose digestibility compared to the batch system [11]. Unfortunately, the flow-through approach consumes large amounts of water, resulting in very high energy requirements for pretreatment and downstream processing, especially at high flow rates. Liu and Wyman [10] proposed a new partial flow pretreatment (PFP) approach which reduced water consumption by $60 \%$ compared to continuous flow operation with still higher xylose sugar yields (84-89\%). However, the degradation products including the sugar-derived and the lignin-derived were not detected and analyzed. In this work, the hemicellulose of SSB decomposition behavior was investigated in a step-change flow rate liquid hot water (SCFLHW) system, and the sugars and their degradation products analysis were carried out to give a more convincing explanation. Moreover, the combined analysis of water-insoluble and soluble fractions in the hydrolysate with Fourier transform-infrared (FT-IR) spectroscopy, scanning electron microscopy (SEM), and gas chromatography-mass spectroscopy (GC-MS) was conducted to disclose the lignin decomposition process instead of single and unconvincing parameter like lignin removal.

\section{Experimental Section}

\section{Materials}

Sweet sorghum bagasse, the solid residues left after solid-state ethanol fermentation, was kindly offered by Beijing Taitiandi Energy Ltd. It was milled using a forage grinder and screened to $18-40$ mesh and dried at $105{ }^{\circ} \mathrm{C}$ to constant weight $(\sim 4 \mathrm{~h})$. The chemical composition of the raw material (on a dry weight basis) was $45.2 \%$ glucan, $25.5 \%$ xylan, $0.98 \%$ arabinan, $16.6 \%$ acid-insoluble lignin, $6.8 \%$ extractives, and $4.92 \%$ others.

Xylose, furfural, acetic acid, glucuronic acid, glycolic acid, and formic acid were purchased from Sigma-Aldrich Company. 


\section{Experimental Setup and Operation}

SCFLHW experiments were carried out using the apparatus depicted in Fig. 1. The experimental system consisted of a flow-through reactor, a feeding system (peristaltic pump of liquid chromatography system and preheating coil), and a product collector. The reactor, sample tank, and all connecting tubes were made of $316 \mathrm{~L}$ stainless steel. The reactor chamber was $40 \mathrm{~mm}$ in diameter and $150 \mathrm{~mm}$ long fitting with a total volume of $188 \mathrm{ml}$. At the beginning of the reaction, the reactor was preheated to about $80^{\circ} \mathrm{C}$. Then, the wetted SSB (about $82 \%$ moisture content) was fed into the reactor. The reactor was sealed quickly and nitrogen gas was flowed into the reactor to maintain the reaction pressure $(5 \mathrm{MPa})$. The reactor reached to $184^{\circ} \mathrm{C}$ within $2 \mathrm{~min}$, and the preheated water was pumped into the reactor with a certain flow rate. When the target running time was reached, the flow was stopped and the reactor was quenched in cold water. The liquid sample was collected from the sample tank. The hydrolysates separated into the water-soluble fraction and the water-insoluble fraction as obtained by centrifugation and filtration were used for further analysis.

\section{Analytical Methods}

The chemical composition of raw material was analyzed according to the standard laboratory analytical procedures (LAP) for biomass analysis provided by the National Renewable

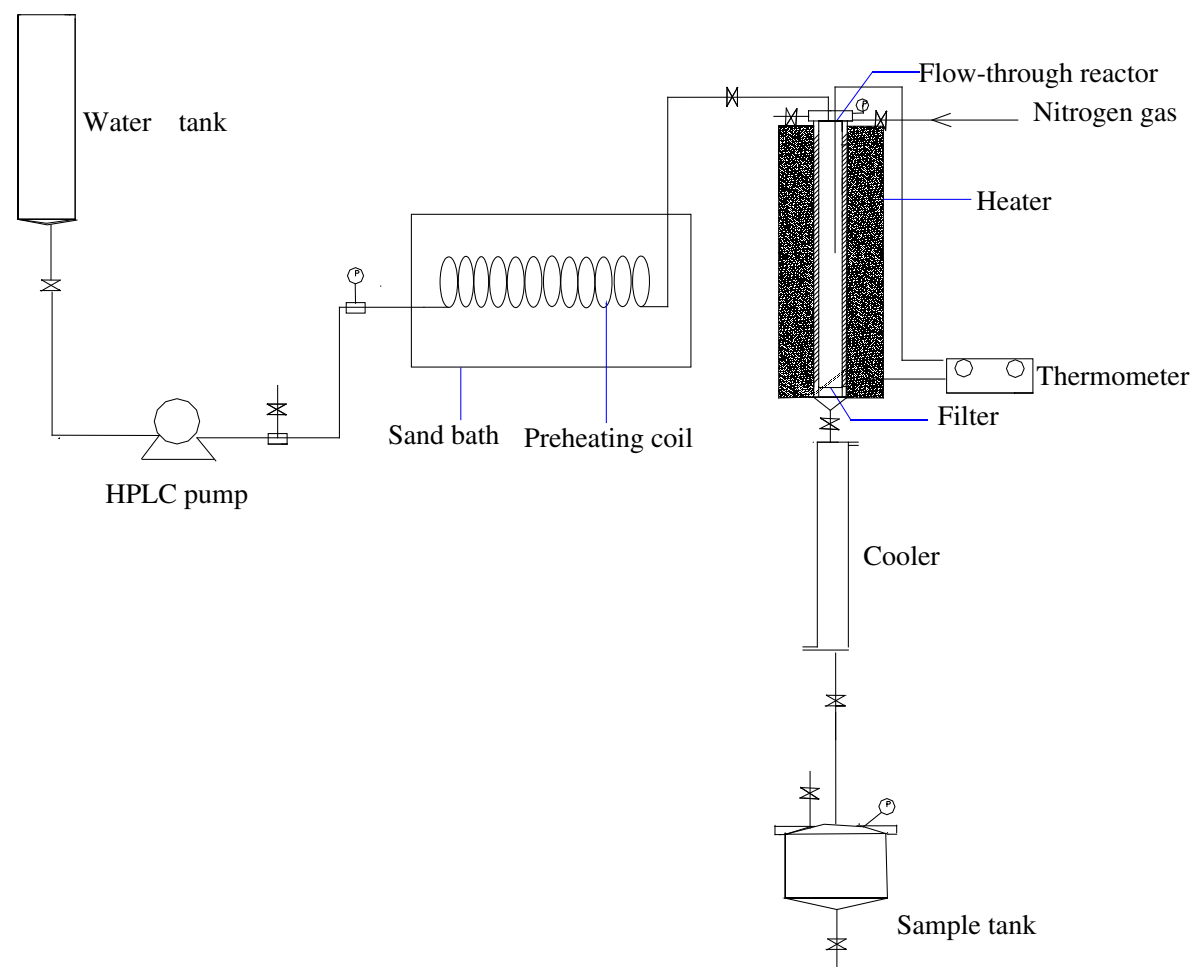

Fig. 1 Experimental setup of SSB hydrolysis reactor 
Energy Laboratory (NREL). Sugars and degradation products (acids and aldehydes) in the hydrolysate were identified on the basis of NREL LAP. The oligomeric sugars in the liquid fraction were back-calculated after a secondary hydrolysis into monomerics with $4 \%$ sulfuric acid. The monomeric sugars and acids in the hydrolysate were determined by HPLC using a Shodex sugar SH-1011 column coupled with a refractive index detector, and furfural and 5$\mathrm{HMF}$ were detected by an ultraviolet detector. The mobile phase was $0.005 \mathrm{M} \mathrm{H}_{2} \mathrm{SO}_{4}$ at a flow rate of $0.5 \mathrm{ml} / \mathrm{min}$, with a column temperature of $50{ }^{\circ} \mathrm{C}$. The total sugar in the liquid sample included the monosaccharide and oligosaccharide. The analysis of degradation products (furfural, acetic acid, glucuronic acid, glycolic acid, and formic acid) was based on the amount of xylose in the untreated biomass material.

Mass spectra were recorded at $70 \mathrm{eV}$ with a Finnigan Trace $2000 \mathrm{GC}-\mathrm{MS}$ instrument. The GC is equipped with 5\% phenyl polymethylsiloxane capillary column DB-5 of $30 \mathrm{~m} \times$ $0.25 \mathrm{~mm}$ ID, film thickness $0.25 \mu \mathrm{m}$ (Agilent Technologies Inc.). The temperature program was $4 \mathrm{~min}$ at $40^{\circ} \mathrm{C}$, then $5^{\circ} \mathrm{C}$ per minute to $200^{\circ} \mathrm{C}$ and held for $2 \mathrm{~min}$, finally to $250^{\circ} \mathrm{C}$ at a rate $20^{\circ} \mathrm{C}$ per minute, and the temperature was held for $4 \mathrm{~min}$. The trimethylsilylated samples prepared following the analytical methodology described by Zafra et al. [24] were injected at a volume of $3.0 \mu \mathrm{l}$. Lignin-derived monomeric products were identified from their mass spectra by comparing their retention time with those of authentic compounds.

The water-insoluble fraction was characterized by FT-IR and SEM. FT-IR spectra were recorded using a Bruker TENSOR-27 spectrophotometer using the $\mathrm{KBr}$ pellet technique. The SEM images were obtained in a Jeol, JSM T-300 apparatus, using an accelerating voltage of $15 \mathrm{kV}$.

\section{Results and Discussion}

\section{The Hydrolysis of Hemicellulose}

In our previous research, the combined effect of reaction temperature $\left(155-235^{\circ} \mathrm{C}\right)$, flow rate $(5-30 \mathrm{ml} / \mathrm{min})$ and running time $(0-60 \mathrm{~min})$ on SSB hemicellulose hydrolysis as treated by flow-through liquid hot water had been evaluated. The optimum hemicellulose hydrolysis conditions were $184^{\circ} \mathrm{C}, 10 \mathrm{ml} / \mathrm{min}$ for $18 \mathrm{~min}$. In addition, it was found that high flow was particularly effective early in hemicellulose hydrolysis and less effective later. Thereby, a SCFLHW process was designed to improve both the sugars recovery and concentration from SSB. A wide flow rate range was selected as $0-30 \mathrm{ml} / \mathrm{min}$ in the first $8 \mathrm{~min}$ respectively followed the next $10 \mathrm{~min}$ with the flow rate of $10 \mathrm{ml} / \mathrm{min}$.

Consistent with the previous reports from Wyman's group [11, 17] that xylan removal increased with flow rate, an increased xylan removal was obtained from less than about $64.53 \%$ for batch system (condition $\mathrm{A}, 184^{\circ} \mathrm{C}, 18 \mathrm{~min}, 4.25 \% \mathrm{w} / \mathrm{v}$ ) to about $83.78 \%$ at high flow rates of $30 \mathrm{ml} / \mathrm{min}$ for $8 \mathrm{~min}$, and then $10 \mathrm{ml} / \mathrm{min}$ for $10 \mathrm{~min}$ (condition F). As presented in Fig. 2a, the yield of total xylose increased greatly with the first-8-min flow rate (lower than $30 \mathrm{ml} / \mathrm{min}$ ), especially at the flow rate from 0 to $10 \mathrm{ml} / \mathrm{min}$ (conditions

Fig. 2 The yield of total xylose and their concentration (a), the yield of xylose monomer and oligomers (b), and the main degradation products (c) in the liquid fractions. ( $\mathrm{A}$ : batch, $4.25 \% \mathrm{w} / \mathrm{v}, 18 \mathrm{~min}, 184^{\circ} \mathrm{C}$; $\mathrm{B}$ : flowthrough, $0 \mathrm{ml} / \mathrm{min}$ for $8 \mathrm{~min}$, then $10 \mathrm{ml} / \mathrm{min}$ for $10 \mathrm{~min}, 184^{\circ} \mathrm{C}$; C: flow-through, $5 \mathrm{ml} / \mathrm{min}$ for $8 \mathrm{~min}$, then $10 \mathrm{ml} / \mathrm{min}$ for $10 \mathrm{~min}, 184^{\circ} \mathrm{C}$; D: flow-through, $10 \mathrm{ml} / \mathrm{min}$ for $8 \mathrm{~min}$, then $10 \mathrm{ml} / \mathrm{min}$ for $10 \mathrm{~min}, 184^{\circ} \mathrm{C}$; E: flow-through, $20 \mathrm{ml} / \mathrm{min}$ for $8 \mathrm{~min}$, then $10 \mathrm{ml} / \mathrm{min}$ for $10 \mathrm{~min}, 184^{\circ} \mathrm{C}$; F: flow-through, $30 \mathrm{ml} / \mathrm{min}$ for $8 \mathrm{~min}$, then $10 \mathrm{ml} / \mathrm{min}$ for $10 \mathrm{~min}, 184^{\circ} \mathrm{C}$ ) 

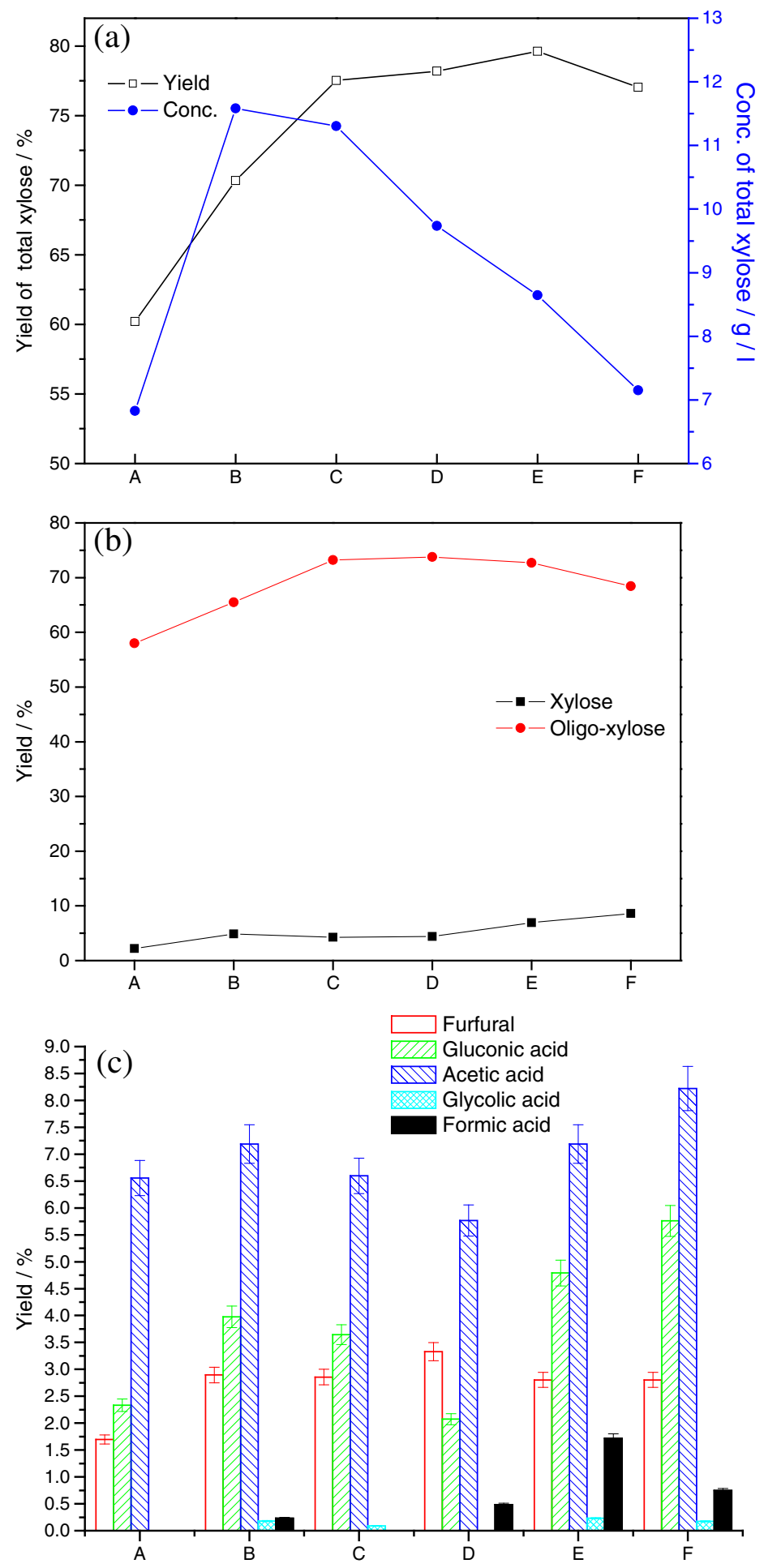
Fig. 3 SEM images $(\times 10,000)$ of lignin droplets found on the surface of pretreated SSB $(\mathbf{b})$ and in the waterinsoluble fraction of hydrolysate (c) after the pretreatment with flow of $20 \mathrm{ml} / \mathrm{min}$ for $8 \mathrm{~min}$ and $10 \mathrm{ml} / \mathrm{min}$ for $10 \mathrm{~min}$ at $184^{\circ} \mathrm{C}$. A micrograph of an unpretreated SSB surface is provided for comparison (a)

$\mathrm{B}, \mathrm{C}, \mathrm{D}$, and E). However, an interesting result was observed that the yield of total xylose decreased when SSB was hydrolyzed at the condition F with the high first-8-min flow rate of $30 \mathrm{ml} / \mathrm{min}$. Figure $2 \mathrm{~b}$ indicates that there was a small increase range of xylose oligomers when the first-8-min flow rate increased from 5 to $20 \mathrm{ml} / \mathrm{min}$, and it dropped at the flow rate of $30 \mathrm{ml} / \mathrm{min}$. In contrast, xylose monomer was observed with the increase of the first-8-min flow rate even at the flow of $30 \mathrm{ml} / \mathrm{min}$, which is an indication of secondary decomposition of the primary products (xylose oligomers) in aqueous phase.

This is similar to the reactions of cellulose in flow-through hot-compressed water [21], the decomposition behavior of hemicellulose under present reaction condition comprises of reactions on the surface of the particle to produce primary products, the dissolution of these primary products into the water, followed by the secondary decomposition of the primary products in aqueous phase. Based on our previous studies, the major xylan in SSB hemicellulose is $O$-acetyl-4- $O$-methyl-glucuronoarabinoxylan. Also, xylose oligomers, glucuronic acid, and acetic acid can be considered as the primary products. Xylose monomer, furfural, glycolic acid, formic acid, etc. are the secondary decomposition products. In other words, the more glucuronic acid and acetic acid are recovered, the more hemicellulose is decomposed. The more glycolic acid and formic acid are detected, the more sugars are degraded. Figure $2 \mathrm{c}$ shows that there were the highest yields of glucuronic acid $(5.76 \%)$ and acetic acid $(8.22 \%)$ at the high first- 8 -min flow rate of $30 \mathrm{ml} / \mathrm{min}$, and the yield of glycolic acid and formic acid reached $0.17 \%$ and $0.75 \%$, respectively. It could be concluded that, on one hand, the high flow rate enhances the hemicellulose decomposition, and on the other hand, a small part of the primary products (xylose oligomers) were further decomposed. Generally, the secondary reaction of the primary products should be minimized due to the low residence time under the higher water flow rate. But, for a SCFLHW process, as expected, soluble oligomers increased at the first-step high flow rate and were rapidly swept out of the reactor system. Thus, the oligomers that remained in the reactor would be further decomposed into monomers in the second-step process with lower flow rate $(10 \mathrm{ml} / \mathrm{min})$. Therefore, SCFLHW process represented the larruping characteristics of high sugar monomer recovery which was beneficial to the ethanol fermentation. This conclusion was supported by Liu and Wyman [10] about the partial flow pretreatment (PFP) of corn stover where the system was first run in the batch mode, followed by flow-through operation for a certain time before returning to batch operation for the remaining time. Taking their experimental results of PFP1 (first run in the batch mode for $4 \mathrm{~min}$, followed by flowthrough operation at a flow rate of $10 \mathrm{ml} / \mathrm{min}$ for $4 \mathrm{~min}$ before returning to batch operation for the remaining $16 \mathrm{~min}$ ) as an example, the xylose monomer to oligomers ratio (xylose monomer concentration/xylose oligomers concentration) was 0.097 which was higher than that (0.074) after the continuous flow operation at a flow rate of $10 \mathrm{ml} / \mathrm{min}$ for $24 \mathrm{~min}$ at the same reaction temperature.

Moreover, compared with the degradation products between the batch processing and flow-through processing, it was found that the former operation had less by-products (Fig. 2c). Therefore, it can be concluded that there is a moderate reaction condition for the batch operation bringing a low total xylose recovery and concentration. The observation is inconsistent with the conventional explanation of low sugars recovery in batch system that the sugars cannot be transferred out of the reactor immediately and degraded into the by- 

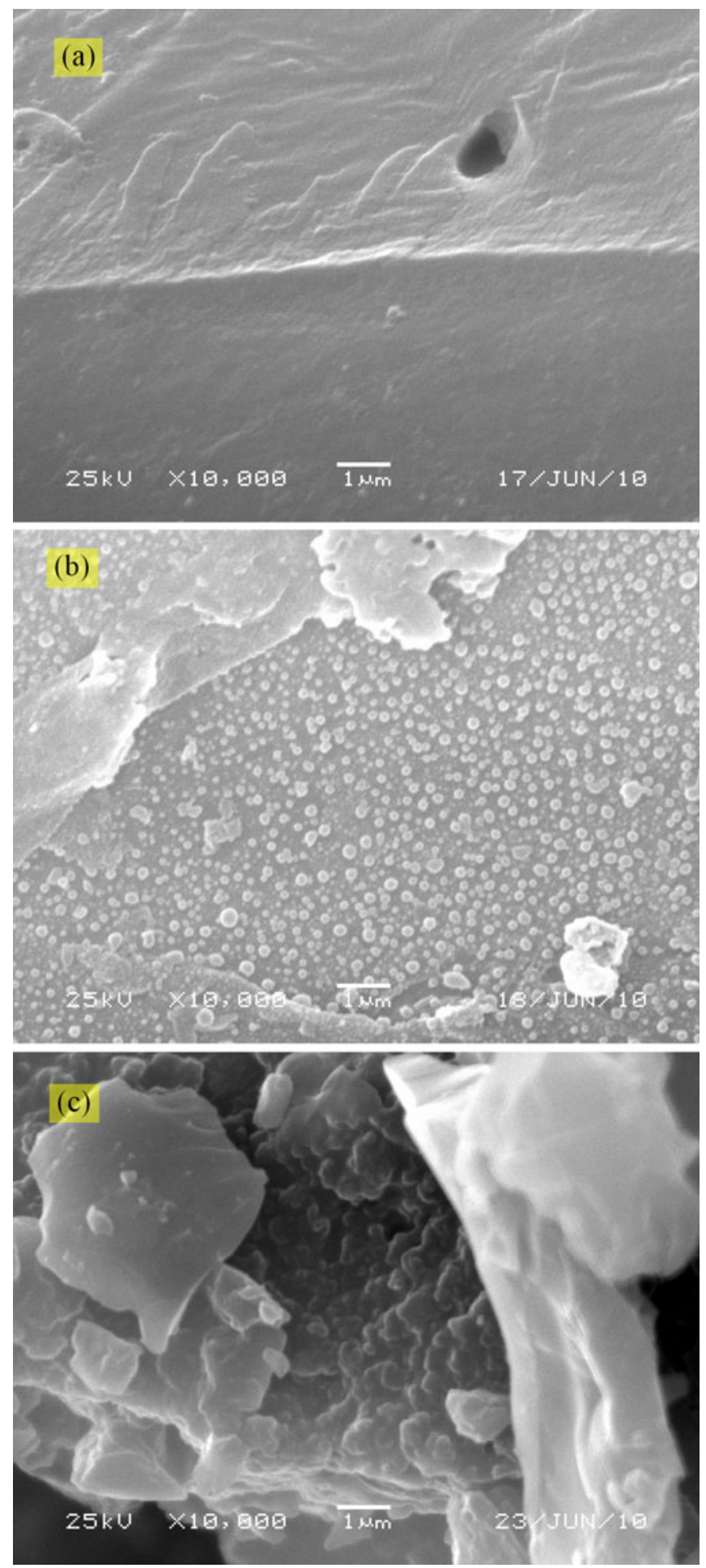
products [23]. On these bases, it was hypothesized that the mass transfer or other physical factors impacted hemicellulose hydrolysis in SCFLHW processing. Flowing water would reduce the thickness of stagnant fluid layer surrounding the solid particles and lower resistance to penetration of water into the solids for hydrolysis and diffusion of oligomers into solution.

\section{The Solubilization of Lignin}

Lignin is generally considered as a formidable barrier to efficient enzymatic breakdown of biomass to sugars [6, 18]. Donohoe et al. [4] pointed out that some mild pretreatment strategies, such as dilute acid and hot water, significantly increased the digestibility of biomass without removing much of the insoluble lignin content. Tracking lignin on and in the biomass cell walls, they proposed that thermochemical pretreatments reaching temperatures above the range for lignin phase transition caused lignin to coalesce into larger molten bodies that migrated within and out of the cell wall, and could redeposit on the surface of plant cell walls. This decompartmentalization and relocalization of lignin was speculated to be as important as lignin removal in the quest to improve the digestibility of biomass for sugars and fuels production.

In the present work, the fate of SSB lignin remaining with the solids after the SCFLHW pretreatment was revealed by SEM imaging. A range of discrete droplet morphologies appeared on the surface of pretreated SSB. Droplets were observed on all pretreated samples from both batch and flow-through processing. Figure $3 \mathrm{~b}$ presents the lignin droplets found on the surface of pretreated SSB after the pretreatment with a flow rate of $20 \mathrm{ml} / \mathrm{min}$ for $8 \mathrm{~min}$ and $10 \mathrm{ml} / \mathrm{min}$ for $10 \mathrm{~min}$ at $184{ }^{\circ} \mathrm{C}$.

Meanwhile, the lignin-derived products in the hydrolysate were determined by FTIR and GC-MS to further explain the lignin decomposition mechanism in SCFLHW systematically and comprehensively. The hydrolysate was separated into two fractions by centrifugation, the water-insoluble fraction and water-soluble fraction. The former was shown to mainly contain lignin and cellulose fragments by FT-IR and a secondary hydrolysis with 4\% sulfuric acid [19]. Moreover, some droplet morphologies were also found in the water-insoluble fraction of hydrolysate (Fig. 3c). It would provide direct evidence that the water-insoluble fraction is the deposits of the flushed lignin. The FTIR spectra of water-insoluble fraction are presented in Fig. 4a. The most characteristic infrared bands of lignin were found at about 1,515 and $1,600 \mathrm{~cm}^{-1}$ representing the aromatic skeletal vibrations. The bands at 1,245 and $1,040 \mathrm{~cm}^{-1}$ are indicative of the aromatic $\mathrm{C}-\mathrm{O}$ stretching vibrations resulting from syringyl ring and primary alcohol, respectively [7]. Moreover, aromatic $\mathrm{C}-\mathrm{H}$ vibrations of syringyl units are at $825 \mathrm{~cm}^{-1}$. To compare the aromatic ring contents of these samples, absorbance was normalized to the highest peak in the fingerprint range. The normalized absorbances $A_{1515} / A_{1040}$ were computed and shown in Fig. 5.

Lignin-derived products in the water-soluble fraction were determined by GC-MS. Figure $4 \mathrm{~b}$ shows the total ion chromatograms of the trimethylsilylated water-soluble portions. It can be speculated that SSB lignin is a $p$-hydroxyphenyl-guaiacyl-syringyl (H-G-S) lignin and contains all of the three monolignol units namely $p$-coumaryl, coniferyl, and sinapyl alcohols in significant amounts like all other herbaceous plants. Lignin is always associated with carbohydrates (in particular with hemicelluloses) via covalent bonds $\alpha-\mathrm{O}-4$ linkages, and this association is called lignin-carbohydrate complexes (LCC). In herbaceous plants, they are often referred to as "lignin/phenolics-carbohydrate" complexes (LPCC) [1]. Ferulic acid is attached to lignin with ether bonds and to 

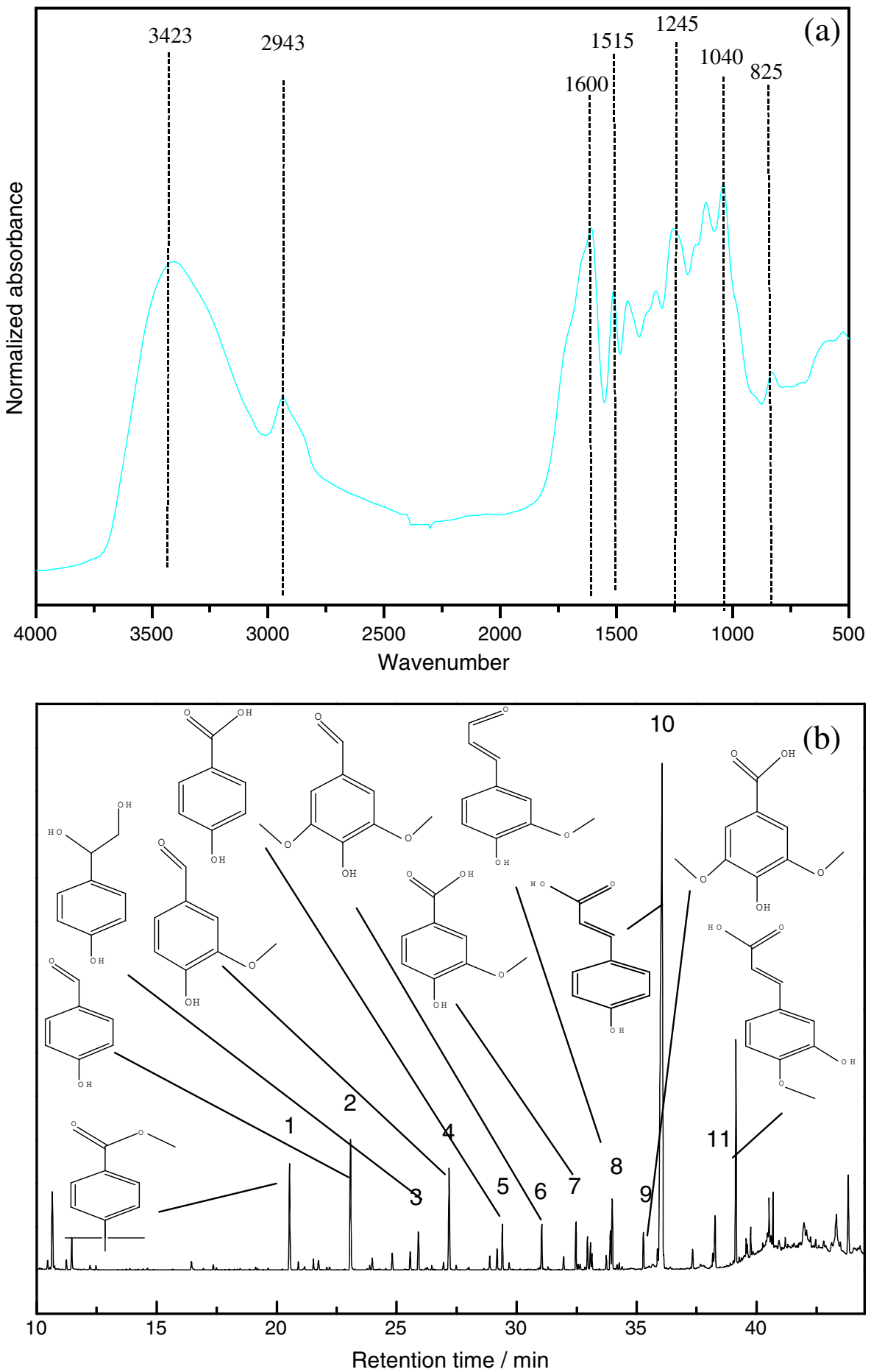

Fig. 4 FT-IR spectra of water-insoluble portions (a). Spectra are normalized to the highest peak of $1,040 \mathrm{~cm}^{-1}$. Total ion chromatograms of the water-soluble portions (b). The reaction condition is the same as in Fig. 3 


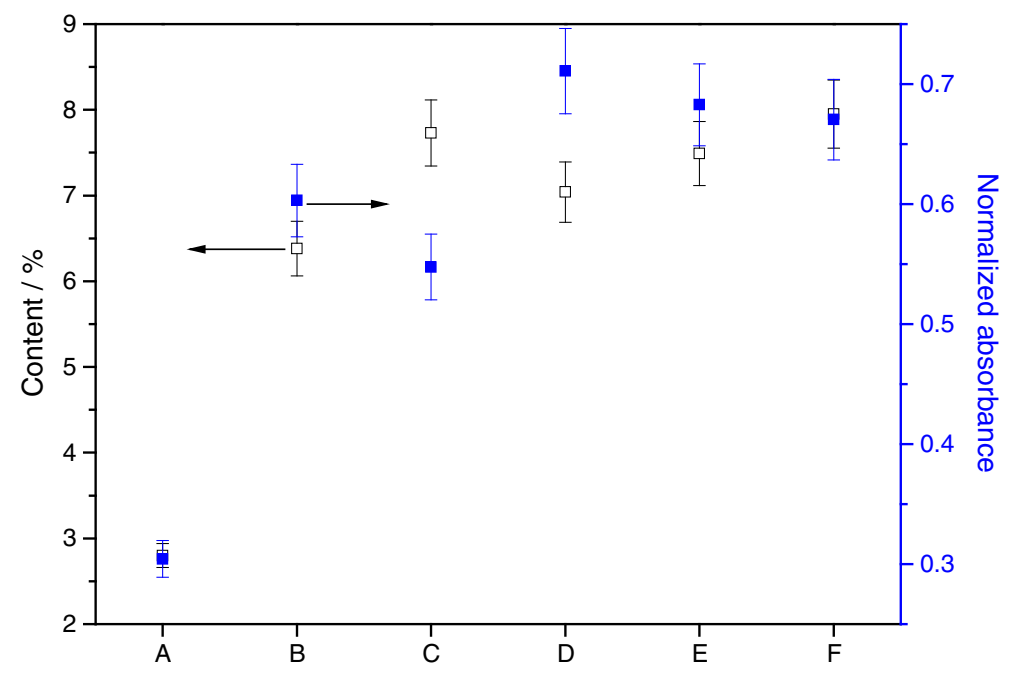

Fig. 5 The relative content of coumaric acid in water-soluble portions and normalized absorbance at $1,515 \mathrm{~cm}^{-1}$ of water-insoluble portions. The reaction condition is the same as in Figure 2

carbohydrates with ester bond as described in Fig. 6. A possible decomposition mechanism of LPCC in SCFLHW was proposed based on the analysis of lignin-derived monomeric products in the water-soluble portion. Due to the acid-base catalytic properties of liquid hot water, base group can cleave the ester bonds between ferulic acid and polysaccharides, liberating the ferulic acid residue and lignin from carbohydrates yielding small amounts of ferulic acid. Acid group is expected to cleave the ether bonds between ferulic acid and lignin. The decomposition products like ferulic acid and coumaric acid would be further oxidatively cleaved into vanillin, vanillic acid, $p$ hydroxybenzaldehyde, and $p$-hydroxybenzoic acid.

As the maximum proportion in the lignin-derived monomeric products, coumaric acid was chosen to evaluate the degradation degree of lignin polymerization. As shown in Fig. 5, the relative content of coumaric acid increased with the first-8-min flow rate. Compared with the relative content of coumaric acid of $2.8 \%$ in batch processing, it increased to $7.95 \%$ in the condition of $\mathrm{F}\left(184^{\circ} \mathrm{C}, 30 \mathrm{ml} / \mathrm{min}\right.$ for $8 \mathrm{~min}$, then $10 \mathrm{ml} / \mathrm{min}$ for $\left.10 \mathrm{~min}\right)$ owing to the severity of the reaction condition. The corresponding results between the relative content of coumaric acid and normalized absorbance at $1,515 \mathrm{~cm}^{-1}$ were observed in Fig. 5, showing that the more lignin polymer was degraded, the less lignin fragments were accumulated as water-insoluble fraction in the hydrolysate.

\section{Conclusions}

The decomposition behavior of hemicellulose in a SCFLHW process is different from the conventional continuous-flow operation. There were a low xylose oligomers recovery and a relative high monomer yield at the high flow rate, such as $30 \mathrm{ml} / \mathrm{min}$, due to the secondary decomposition of xylose oligomers in the second-step low flow rate process. Lignin in the liquid hot water first migrated out of the cell wall in the form of molten bodies and then flushed out of the reactor. A small quantity of them was further degraded into monomeric 

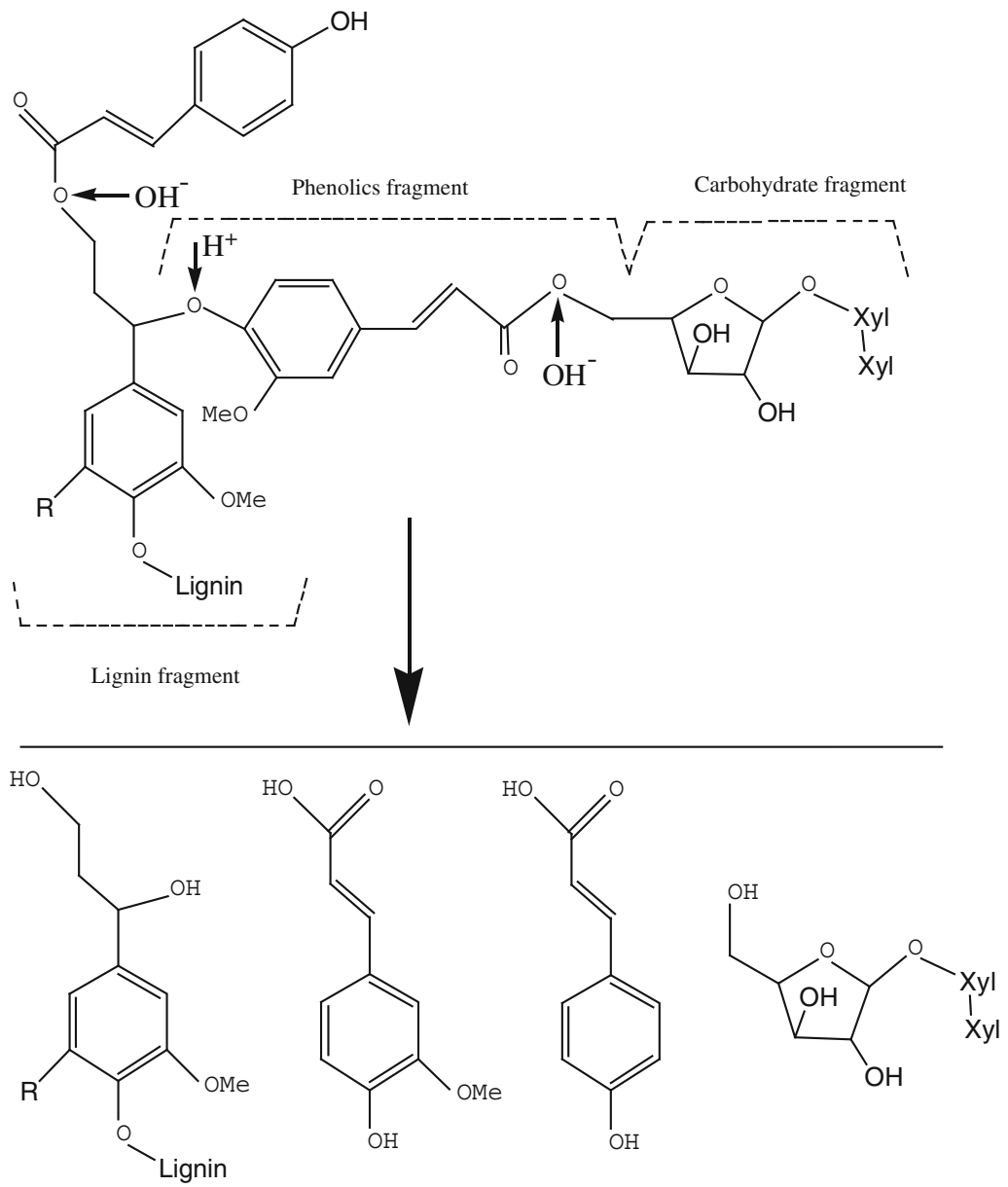

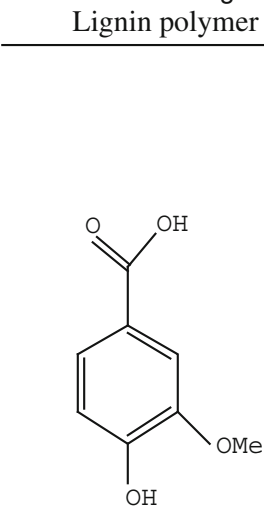

Vanillic acid

Oxidative cleavage
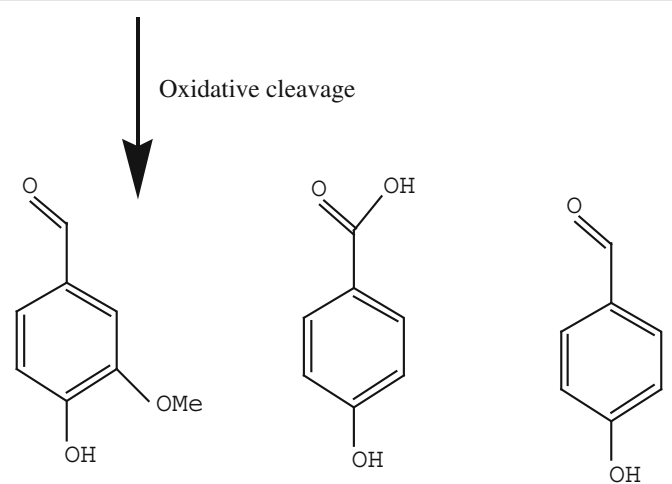

Vanillin p-Hydroxybenzoic acid p-Hydroxybenzaldehyde

Fig. 6 Proposed decomposition mechanism for lignin in liquid hot water 
products such as vanillin, syringe aldehyde, coniferyl aldehyde, ferulic acid, and $p$-hydroxycinnamic acid.

Acknowledgments This work was supported financially by the National Natural Science Foundation of China (no. 51176196 and 51076156) and the National Basic Research Program of China (973 Program) (2012CB215304).

\section{References}

1. Buranov, A. U., \& Mazza, G. (2008). Lignin in straw of herbaceous crops. Industrial Crops and Products, $28,237-259$.

2. Dien, B. S., Li, X. L., Iten, L. B., Jordan, D. B., Nichols, N. N., O'Bryan, P. J., \& Cotta, M. A. (2006). Enzymatic saccharification of hot-water pretreated corn fiber for production of monosaccharides. Enzyme and Microbial Technology, 39, 1137-1144.

3. Dogaris, I., Karapati, S., Mamma, D., Kalogeris, E., \& Kekos, D. (2009). Hydrothermal processing and enzymatic hydrolysis of sorghum bagasse for fermentable carbohydrates production. Bioresource Technology, 100, 6543-6549.

4. Donohoe, B. S., Decker, S. R., Tucker, M. P., Himmel, M. E., \& Vinzant, T. B. (2008). Visualizing lignin coalescence and migration through maize cell walls following thermochemical pretreatment. Biotechnology and Bioengineering, 101, 913-925.

5. Gnansounou, E., Dauriat, A., \& Wyman, C. E. (2005). Refining sweet sorghum to ethanol and sugar: economic trade-offs in the context of North China. Bioresource Technology, 96, 985-1002.

6. Hendriks, A. T. W. M., \& Zeeman, G. (2009). Pretreatments to enhance the digestibility of lignocellulosic biomass. Bioresource Technology, 100, 10-18.

7. Jiang, T. (2009) Lignin. ed. Chemical Industry Press, Beijing.

8. Kim, Y., Mosier, N. S., \& Ladisch, M. R. (2009). Enzymatic digestion of liquid hot water pretreated hybrid poplar. Biotechnology Progress, 25, 340-348.

9. Li, B.-Z., Balan, V., Yuan, Y.-J., \& Dale, B. E. (2010). Process optimization to convert forage and sweet sorghum bagasse to ethanol based on ammonia fiber expansion (AFEX) pretreatment. Bioresource Technology, 101, 1285-1292.

10. Liu, C., \& Wyman, C. E. (2005). Partial flow of compressed-hot water through corn stover to enhance hemicellulose sugar recovery and enzymatic digestibility of cellulose. Bioresource Technology, 96, 19781985.

11. Liu, C. G., \& Wyman, C. E. (2003). The effect of flow rate of compressed hot water on xylan, lignin, and total mass removal from corn stover. Industrial and Engineering Chemistry Research, 42, 5409-5416.

12. Liu, L., Sun, J. S., Kang, L. P., \& Liu, P. (2007). The fuel ethanol production from sweet sorghum stalk. Progress in Chemistry, 19, 1109-1115.

13. Mei, X., Liu, R., Shen, F., \& Wu, H. (2008). Optimization of fermentation conditions for the production of ethanol from stalk juice of sweet sorghum by immobilized yeast using response surface methodology. Energy \& Fuels, 23, 487-491.

14. Qiu, H., Huang, J., Yang, J., Rozelle, S., Zhang, Y., Zhang, Y., \& Zhang, Y. (2010). Bioethanol development in China and the potential impacts on its agricultural economy. Applied Energy, 87, 76-83.

15. Sipos, B., Réczey, J., Somorai, Z., Kádár, Z., Dienes, D., \& Réczey, K. (2009). Sweet sorghum as feedstock for ethanol production: enzymatic hydrolysis of steam-pretreated bagasse. Applied Biochemistry and Biotechnology, 153, 151-162.

16. Wang, F., \& Liu, C.-Z. (2009). Development of an economic refining strategy of sweet sorghum in the Inner Mongolia Region of China. Energy \& Fuels, 23, 4137-4142.

17. Yang, B., \& Wyman, C. E. (2008). Characterization of the degree of polymerization of xylooligomers produced by flowthrough hydrolysis of pure xylan and corn stover with water. Bioresource Technology, 99, 5756-5762.

18. Yu, Q., Zhuang, X., Yuan, Z., Wang, Q., Qi, W., Wang, W., Zhang, Y., Xu, J., \& Xu, H. (2010). Two-step liquid hot water pretreatment of Eucalyptus grandis to enhance sugar recovery and enzymatic digestibility of cellulose. Bioresource Technology, 101, 4895-4899.

19. Yu, Q., Zhuang, X., Yuan, Z., Wang, W., Qi, W., Wang, Q., \& Tan, X. (2011). Step-change flow rate liquid hot water pretreatment of sweet sorghum bagasse for enhancement of total sugars recovery. Applied Energy, 88, 2472-2479. 
20. Yu, Y., \& Wu, H. (2010). Significant differences in the hydrolysis behavior of amorphous and crystalline portions within microcrystalline cellulose in hot-compressed water. Industrial and Engineering Chemistry Research, 49, 3902-3909.

21. Yu, Y., \& Wu, H. (2010). Understanding the primary liquid products of cellulose hydrolysis in hotcompressed water at various reaction temperatures. Energy \& Fuels, 24, 1963-1971.

22. Yun, Yu, Lou, X., \& Wu, H. (2007). Some recent advances in hydrolysis of biomass in hot-compressed water and its comparisons with other hydrolysis methods. Energy \& Fuels, 22, 46-60.

23. Yuqiang, ZhuangXinshu, \& YuanZhenhong. (2009). Kinetics and reactors of lignocellulose hydrolysis with dilute acids. Chemical Industry \& Engineering Progress, 28, 1657-1661.

24. Zafra, A., Juárez, M. J. B., Blanc, R., Navalón, A., González, J., \& Vílchez, J. L. (2006). Determination of polyphenolic compounds in wastewater olive oil by gas chromatography-mass spectrometry. Talanta, 70, $213-218$. 